\title{
Pengetahuan dan Profil Gaya Hidup Sehat pada Orang Dewasa di Pedesaan di Daerah Istimewa Yogyakarta
}

\author{
Aris Widayati ${ }^{1}$, Fenty ${ }^{2}$, Yunita Linawati ${ }^{2}$, Putu D. Christasani ${ }^{1}$ \\ ${ }^{1}$ Social Behavioural and Administrative (SBA), Fakultas Farmasi, Universitas Sanata Dharma, \\ Yogyakarta, Indonesia, ${ }^{2}$ Farmakologi, Fakultas Farmasi, Universitas Sanata Dharma, \\ Yogyakarta, Indonesia
}

\begin{abstract}
Abstrak
Kejadian sindrom metabolik (SM) dan penyakit kardiovaskular (PKV) dipengaruhi oleh gaya hidup sehat sehari-hari. Penelitian ini bertujuan mengeksplorasi profil gaya hidup sehat dan pengetahuan tentang hidup sehat dengan pemberian intervensi edukasi di kalangan masyarakat pedesaan di D.I. Yogyakarta. Penelitian ini bersifat eksperimental semu dengan desain potong lintang. Variabel yang diteliti adalah profil gaya hidup sehat dan pengetahuan tentang gaya hidup sehat sebelum dan setelah edukasi tentang gaya hidup sehat. Sampel penelitian dipilih secara non-random purposive dengan kriteria inklusi yaitu penduduk dewasa sehat, di dua dusun yaitu Tanjung dan Dlingseng, Desa Banjaroyo, Kecamatan Kalibawang, Kabupaten Kulonprogo, D.I. Yogyakarta. Data dikumpulkan pada bulan Juli-Agustus 2019 dengan kuesioner yang telah diujicoba, kemudian dianalisis secara deskriptif dan komparatif. Sebanyak 108 responden berpartisipasi dalam penelitian ini. Sebagian besar responden merupakan perempuan (63,9\%), median usia 54 tahun (rentang: 27-76 tahun), dan memiliki tingkat pendidikan tergolong rendah $(82,4 \%)$. Profil gaya hidup sehat secara umum baik, yaitu lebih dari $50 \%$ responden tidak merokok, aktif secara fisik, tidak minum alkohol, menu harian rendah glukosa, rendah kolesterol, dan tinggi serat sayur dan buah. Sebanyak $64,1 \%$ responden mempunyai tingkat pengetahuan tentang gaya hidup sehat pada kategori tinggi. Namun, variabel tingkat pengetahuan tidak berasosiasi dengan semua variabel profil gaya hidup sehat, kecuali variabel aktivitas fisik. Edukasi mampu meningkatkan pengetahuan secara signifikan dengan rata-rata skor sebelum edukasi 7,0, setelah edukasi 8,0, dan satu bulan setelah edukasi 9,0 ( $\mathrm{p}=0,000)$. Edukasi penting dilakukan untuk menjamin keberlanjutan gaya hidup sehat tersebut.
\end{abstract}

Kata kunci: Gaya hidup sehat, intervensi edukasi, kardiovaskular, pedesaan, pengetahuan

\section{Knowledge and Profiles of Healthy Lifestyle among Adults in Rural Area of Yogyakarta Province Indonesia}

\begin{abstract}
Metabolic syndrome (MS) and cardiovascular diseases (CVD) are influenced by healthy lifestyle. The purpose of this study is to explore healthy lifestyle profiles and knowledge amongst the rural inhabitants of D.I. Yogyakarta, through education intervention. This is a quasi-experimental research with crosssectional design, and the observed variables include healthy lifestyle and knowledge before and after the intervention. In addition, samples were selected by non-random purposive technique, and the inclusion criteria were adults living in the predetermined villages of Tanjung and Dlingseng, Banjaroyo, Kalibawang, Kulonprogo, D.I. Yoyakarta. The data were collected from July to August 2019 using a pre-tested questionnaire, prior to analysis with descriptive and comparative statistics. A total of 108 respondents participated in this study, comprising majorly females $(63.9 \%)$, with a median age of 54 years (range: $27-76$ years old), while $82.4 \%$ were in the lower education level. The results show a generally good healthy lifestyle profiles, as over $50 \%$ of respondents had no history of smoking and alcohol consumption. Also, most participants had a good level of physical activity, low glucose and cholesterol, alongside a high consumption of fiber foods from fruits and vegetables. In addition, about $64.1 \%$ of respondents had substantial related knowledge, despite the absence of any significant associations with all variables, except physical activity. The levels of knowledge significantly differed between before and after education intervention, evidenced by mean scores of 7.0 and 8.0, respectively. Furthermore, 9.0 was recorded at one month after $(\mathrm{p}=0.000)$, thus intervention was considered important, especially to maintain healthy habits.
\end{abstract}

Keywords: Education, healthy life style, knowledge, rural

Korespondensi: apt. Aris Widayati, M.Si., PhD., Social Behavioural and Administrative (SBA), Fakultas Farmasi, Universitas Sanata Dharma, Yogyakarta, D.I. Yogyakarta 55284, Indonesia, email: ariswidayati31@gmail.com; ariswidayati@usd.ac.id

Naskah diterima: 27 September 2019, Diterima untuk diterbitkan: 2 Juni 2020, Diterbitkan: 29 Juni 2020 


\section{Introduction}

Individu dengan sindrom metabolik (SM) berisiko dua kali lipat mengalami penyakit kardiovaskular (PKV) dibandingkan dengan individu yang tanpa SM. ${ }^{1}$ Selain itu, penyakit diabetes melitus tipe 2 juga ditingkatkan risikonya dengan SM. ${ }^{2}$ Prevalensi SM di beberapa kota besar di Indonesia berada pada rentang $15 \%$ sampai $40 \%,{ }^{3-7}$ sedangkan di daerah perkotaan sebesar $17,5 \%,{ }^{8}$ dan pada masyarakat pedesaan sebesar 25\%. ${ }^{9}$ Rata-rata persentase PKV secara nasional berdasarkan data Riskesdas tahun 2018 sebesar 1,5\% dan D.I. Yogyakarta menempati urutan ketiga di antara semua provinsi dengan persentase di atas rata-rata nasional. ${ }^{10}$

Kejadian SM dan PKV dapat dicegah dengan memodifikasi faktor risiko yang dapat diperbaiki (modifiable risk factor). Salah satu modifiable risk factor adalah gaya hidup yang tidak sehat. Perubahan gaya hidup, misalnya: mengurangi makanan berlemak, meningkatkan aktivitas fisik, serta mengontrol berat badan adalah upaya penatalaksanaan bagi seseorang yang didiagnosis SM.,11 $\mathrm{Hal}$ tersebut berkontribusi pada penurunan faktor risiko seseorang berada pada kondisi SM, yaitu: adanya obesitas abdominal, peningkatan kadar trigliserida darah, penurunan kadar kolesterol high density lipoprotein (HDL), peningkatan tekanan darah, dan peningkatan glukosa darah. ${ }^{12}$

Sebuah penelitian sebelumnya telah dilakukan di populasi masyarakat pedesaan di Desa Banjaroyo, Kalibawang, Kulonprogo, D.I. Yogyakarta. ${ }^{13}$ Hasil penelitian tersebut menunjukkan bahwa secara sosio-demografi mereka merupakan masyarakat produktif (median usia: 51 tahun), dengan pekerjaan bertani (99\%), dan sebagian besar responden memiliki tingkat pendidikan terakhir yang tergolong rendah $(82,3 \%)$ yaitu Sekolah Menengah Pertama (SMP) atau di bawahnya, bahkan tidak pernah bersekolah. Sebagian besar responden dalam penelitian tersebut menyatakan telah mempraktikkan gaya hidup sehat $(67,7 \%)$, sebanyak $56,5 \%$ responden memiliki tingkat pengetahuan yang tinggi, dan $66,1 \%$ bersikap positif terkait gaya hidup sehat. Gambaran risiko SM yang dominan pada populasi tersebut yaitu: sebesar $55,6 \%$ responden penelitian mengalami obesitas sentral; median tekanan darah sistol di atas normal dan diastol normal; median gula darah puasa dan kolesterol normal. Namun hasil penelitian tersebut menunjukkan adanya hubungan yang kontradiktif antara beberapa variabel pengetahuan, sikap, tindakan (PST) tentang gaya hidup sehat dengan faktor risiko SM. Misalnya, variabel PST tentang gaya hidup sehat dengan kadar gula darah puasa yang berkorelasi positif, seharusnya arah korelasinya negatif; demikian juga antara PST dan indeks massa tubuh. Selain itu, penelitian tersebut juga membahas tentang kemungkinan fenomena adanya niat dari responden untuk mempraktikkan gaya hidup sehat sehari-hari namun tidak dilakukan secara benar karena mungkin pengaruh kebiasaan setempat atau persepsi yang keliru. Contohnya, kebiasaan "minum teh" yang berarti adalah teh manis, atau persepsi keliru bahwa pekerjaan rumah tangga dan "di ladang" dianggap sebagai aktivitas olahraga rutin. Padahal, berdasarkan World Health Organization (WHO), aktivitas fisik secara teratur adalah melakukan olahraga atau gerakan tubuh selama minimal 30 menit secara terus-menerus dan teratur minimal lima kali dalam seminggu. ${ }^{14}$

Penelitian Widayati, dkk. ${ }^{13}$ yang disebutkan di atas merekomendasikan strategi intervensi berupa edukasi mengenai gaya hidup sehat yang mengakomodasi faktor-faktor kebiasaan hidup di daerah setempat, terutama yang terkait dengan kearifan lokal. Oleh karena itu, penelitian ini, yang merupakan penelitian lanjutan dari Widayati, dkk., ${ }^{13}$ bertujuan untuk memberikan edukasi tentang gaya hidup sehat dan mengevaluasi peningkatan pengetahuan 
terkait gaya hidup sehat sebelum dan sesudah edukasi di kalangan masyarakat pedesaan di Desa Banjaroyo, Kalibawang, Kulonprogo, D.I. Yogyakarta.

\section{Metode}

Penelitian ini bersifat eksperimental semu dengan desain potong lintang. Pengambilan data dilakukan pada bulan Juli-Agustus 2019 di dua dusun, yaitu Dusun Tanjung dan Dusun Dlingseng di Desa Banjaroyo, Kecamatan Kalibawang, Kabupaten Kulonprogo, Provinsi D.I. Yogyakarta. Penelitian telah dinyatakan laik etik oleh Komite Etik Penelitian Kesehatan Fakultas Kedokteran Universitas Kristen Duta Wacana Yogyakarta dengan no. 1064/C.16/F $\mathrm{K} / 2019$.

Besar sampel dan teknik sampling

Teknik pemilihan responden pada penelitian ini dilakukan secara non-random purposive. Kriteria inklusi responden adalah penduduk dewasa yang berusia antara 30 sampai 75 tahun, sehat jasmani dan rohani (berdasarkan pernyataan responden), dan bersedia untuk berpartisipasi secara sukarela dan dibuktikan dengan menandatangani informed consent. Wanita hamil dinyatakan masuk ke dalam kriteria eksklusi. Jumlah responden merupakan populasi terjangkau yang ditentukan berdasar pada penelitian sebelumnya, yaitu sebanyak 124. ${ }^{13}$ Responden juga telah diberi penjelasan singkat tentang penelitian ini.

Variabel, instrumen penelitian, dan pengukuran variabel penelitian

Variabel dalam penelitian ini adalah profil sosio-demografi yang meliputi: gender, umur, dan pendidikan terakhir; profil gaya hidup sehat, yaitu: status merokok, aktivitas fisik, status minum alkohol, menu harian rendah glukosa, menu harian rendah kolesterol, dan menu harian tinggi serat dari buah dan sayur. Pertanyaan pada profil gaya hidup sehat tersebut ditanyakan untuk aktivitas dalam satu minggu terakhir. Intervensi edukasi menjadi variabel bebas dalam penelitian ini, sedangkan tingkat pengetahuan tentang gaya hidup sehat sebagai variabel terikat.

Instrumen yang digunakan untuk pengambilan data adalah kuesioner yang telah diuji coba sebelum digunakan. Kuesioner ini diuji untuk validitas isi secara professional judgement, uji pemahaman bahasa kepada 5 orang, dan uji reliabilitas kepada 30 orang dengan karakteristik yang mirip dengan responden penelitian. Nilai Cronbach alpha yang diperoleh dari uji reliabilitas adalah sebesar 0,72 , sehingga dapat dikatakan bahwa kuesioner tersebut reliabel. ${ }^{15}$

Proses pengambilan data dan analisis data Pengambilan data dilakukan pada bulan Juli sampai Agustus 2019. Waktu pengambilan data telah diinformasikan sebelumnya kepada seluruh responden penelitian melalui surat undangan. Pengambilan data dilakukan secara bersamaan untuk seluruh responden di rumah Kepala Dusun. Alur tahap pengambilan data adalah sebagai berikut: dilakukan pengisian kuesioner untuk seluruh data yang meliputi sosio-demografi, profil gaya hidup sehat, dan pengetahuan tentang hidup sehat (pre-test). Kemudian dilakukan edukasi berupa ceramah dibantu dengan pembagian leaflet yang berisi informasi gaya hidup sehat. Tahap berikutnya, dilakukan pengisian kuesioner untuk data pengetahuan tentang gaya hidup sehat (posttest 1). Selang satu bulan kemudian, dilakukan pengisian kuesioner untuk data pengetahuan tentang gaya hidup sehat (post-test 2).

Data dimasukkan, diolah, dan disimpan di program SPSS versi 26. Data dianalisis secara deskriptif yang meliputi frekuensi, persentase, rata-rata, dan median untuk masing-masing variabel. Variabel pengetahuan dikategorikan berdasarkan Bloom's cut-off points yang dimodifikasi menjadi dua tingkat; yaitu tinggi apabila nilai jawaban benar $\geq 7$ dari total 10 dan 
rendah apabila $<7$ dari total 10 . Bloom 's cut-off points ini lazim digunakan untuk penentuan klasifikasi tingkat pengetahuan responden pada berbagai topik, termasuk pengetahuan tentang gaya hidup sehat. ${ }^{16,17}$ Uji Chi-Square digunakan untuk menganalisis perbedaan proporsi antara kategori pada variabel profil sosio-demografi dan gaya hidup sehat dengan tingkat pengetahuan. Analisis selanjutnya yaitu menguji pengaruh intervensi edukasi terhadap tingkat pengetahuan pada sampel berpasangan dengan uji Wilcoxon signed rank test, karena sebaran data tidak normal. Pada uji Wilcoxon signed rank test ini, data yang diperbandingkan adalah data tingkat pengetahuan hasil pre-test (sebelum edukasi) dengan hasil post-test 1 (setelah edukasi), hasil pre-test dengan hasil post-test 2 (satu bulan setelah edukasi), dan hasil post-test 1 dengan hasil post-test 2 .

\section{Hasil}

Terdapat 108 responden yang terlibat dalam penelitian ini dari total 124 populasi terjangkau yang diundang untuk berpartisipasi (response rate: $87 \%$ ). Karakteristik sosiodemografi responden dan profil gaya hidup sehat responden dapat dilihat pada Tabel 1 . Respoden perempuan pada penelitian ini lebih banyak dari pria yaitu $63,9 \%$. Median usia responden adalah 54 tahun (rentang: 2776 tahun). Sebagian besar responden $(82,4 \%)$ berpendidikan rendah (lulusan SMP, Sekolah Dasar (SD), dan tidak bersekolah). Profil gaya hidup sehat responden pada penelitian ini secara umum dapat dikatakan baik. Lebih dari $50 \%$ responden laki-laki tidak merokok dan semua responden perempuan tidak merokok. Sebanyak 89,8\% responden menyatakan aktif secara fisik. Hampir semua responden $(98,1 \%)$ tidak minum alkohol dan 95,4\% menyatakan menu makanan hariannya tinggi serat dari sayur dan buah. Namun mereka yang menyatakan menu hariannya tidak tinggi glukosa dan tidak tinggi kolesterol hampir seimbang dengan mereka yang menyatakan sebaliknya, yaitu masing-masing 53,7\%. Sebagian besar responden pada penelitian ini mempunyai tingkat pengetahuan yang tinggi tentang gaya hidup sehat, yaitu $64,1 \%$.

Hasil analisis komparatif terhadap proporsi pada masing-masing kategori di profil sosiodemografi dan gaya hidup sehat dengan proporsi di tingkat pengetahuan menunjukkan seluruhnya tidak signifikan secara statistik, kecuali variabel aktivitas fisik. Berdasarkan hasil tersebut, hanya variabel aktivitas fisik saja yang secara signifikan memiliki asosiasi dengan tingkat pengetahuan tentang gaya hidup sehat $(p=0,034)$. Hal ini berarti bahwa terdapat perbedaan bermakna antara proporsi mereka yang aktif dan tidak aktif dalam hal tingkat pengetahuan yang tinggi dan rendah tentang gaya hidup sehat. Untuk variabelvariabel sosio-demografi dan profil gaya hidup sehat yang lain tidak terdapat asosiasi yang bermakna dengan tingkat pengetahuannya. Temuan yang menarik adalah bahwa proporsi dari responden yang aktif secara fisik namun memiliki pengetahuan rendah cukup besar, yaitu sebesar 71,3\%. Rincian hasil komparasi proporsi tersebut dapat dilihat pada Tabel 2 .

Pada Tabel 3, dapat dilihat hasil analisis perbedaan tingkat pengetahuan tentang gaya hidup sehat antara sebelum edukasi dengan setelah edukasi, dan satu bulan setelahnya. Seluruh responden $(\mathrm{N}=108)$ mengikuti rangkaian penelitian ini sampai pengambilan data terakhir, yaitu pada satu bulan setelah intervensi edukasi. Nilai median pengetahuan sebelum edukasi sebesar 7,0 (dari total 10), lalu naik menjadi 8,0 setelah edukasi, dan 9,0 setelah satu bulan edukasi. Hasil komparasi tingkat pengetahuan terhadap intervensi edukasi, yaitu saat sebelum edukasi dengan setelah edukasi, sebelum edukasi dan satu bulan setelah edukasi, dan setelah edukasi dan satu bulan setelahnya, diperoleh hasil terdapat perbedaan yang signifikan dengan 
Tabel 1 Karateristik Sosio-Demografi, Deskripsi Profil Gaya Hidup Sehat, dan Deskripsi Tingkat Pengetahuan tentang Gaya Hidup Sehat pada Masyarakat Pedesaan di Desa Banjaroyo, Kabupaten Kulonprogo, D.I. Yogyakarta, Indonesia ( $\mathrm{N}=108)$

\begin{tabular}{|c|c|}
\hline Karakteristik & Median (Rentang)/Frekuensi $(\%)(\mathrm{N}=108)$ \\
\hline \multicolumn{2}{|l|}{ Sosio-Demografi } \\
\hline Umur (tahun) & Median: $54(27-76)$ \\
\hline$<54$ tahun & $52(48,1 \%)$ \\
\hline$\geq 54$ tahun & $56(51,9 \%)$ \\
\hline \multicolumn{2}{|l|}{ Gender } \\
\hline Laki-laki & $39(36,1 \%)$ \\
\hline Perempuan & $69(63,9 \%)$ \\
\hline \multicolumn{2}{|l|}{ Tingkat Pendidikan } \\
\hline Tinggi (Sekolah Menegah Umum ke atas) & $19(17,6 \%)$ \\
\hline Rendah (di bawah Sekolah Menengah Umum) & $89(82,4 \%)$ \\
\hline \multicolumn{2}{|l|}{ Profil Gaya Hidup Sehat } \\
\hline \multicolumn{2}{|l|}{ Status merokok } \\
\hline Bukan perokok & $89(82,4 \%)$ \\
\hline Perokok & $19(17,6 \%)$ \\
\hline \multicolumn{2}{|l|}{ Status aktivitas fisik } \\
\hline Aktif & $97(89,8 \%)$ \\
\hline Tidak aktif & $11(10,2 \%)$ \\
\hline \multicolumn{2}{|l|}{ Status minum alkohol } \\
\hline Tidak minum & $106(98,1 \%)$ \\
\hline Minum & $2(1,9 \%)$ \\
\hline \multicolumn{2}{|l|}{ Status menu makanan tinggi glukosa } \\
\hline Tidak tinggi glukosa & $58(53,7 \%)$ \\
\hline Tinggi glukosa & $50(46,3 \%)$ \\
\hline \multicolumn{2}{|l|}{ Status menu makanan tinggi kolesterol } \\
\hline Tidak tinggi kolesterol & $58(53,7 \%)$ \\
\hline Tinggi kolesterol & $50(46,3 \%)$ \\
\hline \multicolumn{2}{|l|}{ Status menu makanan tinggi serat dari sayur dan buah } \\
\hline Tinggi serat & $103(95,4 \%)$ \\
\hline Tidak tinggi serat & $5(4,6 \%)$ \\
\hline \multicolumn{2}{|l|}{ Tingkat Pengetahuan tentang Gaya Hidup Sehat } \\
\hline \multicolumn{2}{|l|}{ Sebelum edukasi (pre-test) } \\
\hline Tinggi* & $82(64,1 \%)$ \\
\hline Rendah** & $26(20,3 \%)$ \\
\hline
\end{tabular}

*Skor jawaban benar $\geq 7$ dari total 10

$* *$ Skor jawaban benar $<7$ dari total 10

masing-masing $\mathrm{p}=0,000$ dan size effect kategori medium. Hal tersebut menunjukkan bahwa intervensi edukasi dapat meningkatkan pengetahuan responden, bahkan sampai satu bulan berikutnya.

\section{Pembahasan}

Penelitian ini memberikan hasil yang dapat diringkas sebagai berikut: 1) Profil sosio- demografi responden adalah sebagian besar perempuan, dengan median usia 54 tahun dan berpendidikan di bawah SMU; 2) Profil gaya hidup sehat sebagian besar responden dapat dikatakan baik; 3) Tingkat pengetahuan sebagian besar responden tentang gaya hidup sehat adalah tinggi; 4) Hanya variabel aktivitas fisik yang mempunyai perbedaan proporsi yang signifikan dengan kelompok yang berpengetahuan tinggi dan rendah; dan 
Tabel 2 Perbedaan Profil Sosio-Demografi dan Gaya HidupSehat terhadap Tingkat Pengetahuan tentang Gaya Hidup Sehat pada Masyarakat Pedesaan di Desa Banjaroyo, Kabupaten Kulonprogo, D.I. Yogyakarta, Indonesia (N=108); Dianalisis dengan Chi-square

\begin{tabular}{|c|c|c|c|}
\hline \multirow{2}{*}{$\begin{array}{l}\text { Profil Sosio-Demografi } \\
\text { dan Gaya Hidup Sehat }\end{array}$} & \multicolumn{2}{|c|}{$\begin{array}{l}\text { Proporsi Tingkat Pengetahuan } \\
\text { tentang Gaya Hidup Sehat (\%) }\end{array}$} & \multirow{2}{*}{ p-value } \\
\hline & Tinggi & Rendah & \\
\hline \multicolumn{4}{|l|}{ Usia } \\
\hline$\geq 54$ tahun & 15,7 & 36,1 & 0,174 \\
\hline$<54$ tahun & 8,3 & 39,8 & \\
\hline \multicolumn{4}{|l|}{ Jenis Kelamin } \\
\hline Laki-laki & 11,1 & 25,0 & 0,323 \\
\hline Perempuan & 13,0 & 50,9 & \\
\hline \multicolumn{4}{|l|}{ Tingkat Pendidikan } \\
\hline Tinggi & 1,9 & 15,7 & 0,220 \\
\hline Rendah & 22,2 & 60,2 & \\
\hline \multicolumn{4}{|l|}{ Status Merokok } \\
\hline Bukan perokok & 18,5 & 63,9 & 0,584 \\
\hline Perokok & 5,6 & 12,0 & \\
\hline \multicolumn{4}{|l|}{ Aktivitas Fisik } \\
\hline Aktif & 18,5 & 71,3 & $0,034^{*}$ \\
\hline Tidak aktif & 5,6 & 4,6 & \\
\hline \multicolumn{4}{|l|}{ Status Alkohol } \\
\hline Tidak minum alkohol & 24,1 & 74,1 & 1,00 \\
\hline Minum alkohol & 0,0 & 1,9 & \\
\hline \multicolumn{4}{|c|}{ Kandungan Gula pada Menu Makanan } \\
\hline Rendah gula & 12,0 & 41,7 & 0,834 \\
\hline Tinggi gula & 12,0 & 34,3 & \\
\hline \multicolumn{4}{|c|}{ Kandungan Kolesterol pada Menu Makanan } \\
\hline Rendah kolesterol & 10,2 & 43,5 & 0,266 \\
\hline Tinggi kolesterol & 13,9 & 32,4 & \\
\hline \multicolumn{4}{|c|}{ Kandungan Serat pada Menu Makanan } \\
\hline Tinggi serat & 21,2 & 74,1 & 0,165 \\
\hline Rendah serat & 2,8 & 1,9 & \\
\hline
\end{tabular}

5) Intervensi edukasi mampu meningkatkan pengetahuan secara signifikan dengan ratarata skor 7,0 sebelum edukasi menjadi 8,0 setelah edukasi, dan 9,0 satu bulan setelah edukasi.

Data Riskesdas tahun 2013 menunjukkan bahwa risiko PKV lebih tinggi terjadi pada masyarakat berpendidikan rendah dibanding yang berpendidikan tinggi. ${ }^{18}$ Hasil penelitian ini menunjukkan bahwa meskipun sebagian besar responden berpendidikan rendah tetapi mempunyai profil gaya hidup sehat yang baik dan tingkat pengetahuan tentang gaya hidup sehat juga tinggi. Hasil penelitian terdahulu pada populasi yang sama juga menunjukkan hal yang serupa, yaitu profil gaya hidup sehat baik dan pengetahuannya tentang gaya hidup sehat tergolong tinggi. ${ }^{13}$ Pada hasil penelitian sebelumnya juga diungkapkan bahwa faktor risiko sindrom metabolik di populasi tersebut rendah. Faktor risiko tersebut adalah kadar kolesterol total, kadar gula darah puasa, ukuran lingkar pinggang, dan tekanan darah berada dalam rentang nilai normal; kecuali bahwa ditemukan sebagian besar responden perempuan mengalami obesitas sentral. ${ }^{13}$ 
Tabel 3 Perbedaan Tingkat Pengetahuan tentang Gaya Hidup Sehat Sebelum dan Setelah Edukasi pada Masyarakat Pedesaan di Desa Banjaroyo, Kabupaten Kulonprogo, D.I. Yogyakarta, Indonesia (N=108); Dianalisis dengan Wilcoxon Signed Rank Test

\begin{tabular}{lccc}
\hline \multicolumn{1}{c}{ Tingkat Pengetahuan } & Median & Nilai Z dan r (Effect Size) & p-value \\
\hline Sebelum edukasi & 7,0 & $-3,995$ dan 0,27 (medium effect) & 0,000 \\
Setelah edukasi (pada hari yang sama) & 8,0 & & \\
Sebelum edukasi & 7,0 & $-6,267$ dan 0,43 (medium effect) & 0,000 \\
Satu bulan setelah edukasi & 9,0 & & 0,000 \\
Setelah edukasi (pada hari yang sama) & 8,0 & $-4,318$ dan 0,29 (medium effect) & \\
Satu bulan setelah edukasi & 9,0 & & \\
\hline
\end{tabular}

Hasil ini sejalan dengan yang ditemukan oleh Eguchi, et al. ${ }^{11}$ melalui studi kohort yang dilakukan di Jepang, bahwa faktor yang berkontribusi pada besar atau kecilnya risiko PKV bukanlah tingkat pendidikan seseorang, melainkan praktik gaya hidup sehat yang diterapkan oleh individu tersebut dalam kehidupan sehari-harinya. Melalui penelitian ini dan penelitian sebelumnya, dibuktikan bahwa populasi masyarakat Desa Banjaroyo walaupun sebagian besar memiliki pendidikan formal rendah, namun profil praktik gaya hidup sehat dapat dikatakan baik, dan profil faktor risiko SM relatif rendah. ${ }^{13}$ Namun, penting untuk digarisbawahi bahwa hasil ini tidak dapat digeneralisasi untuk masyarakat pedesaan di seluruh wilayah Indonesia. Selain disebabkan faktor sampel yang tidak mewakili cakupan semua wilayah pedesaan di Indonesia, juga karena tiap-tiap daerah pedesaan mempunyai karakteristik sosial, budaya, dan kearifan lokal masing-masing yang memengaruhi gaya hidup dan kebiasaan sehari-hari masyarakatnya.

Hal yang menarik dari hasil penelitian ini adalah bahwa di antara semua variabel profil gaya hidup sehat, yaitu: status merokok, status minum alkohol, menu makanan rendah glukosa, menu makanan rendah kolesterol, dan menu makanan tinggi serat dari sayur dan buah, tidak berasosiasi secara signifikan dengan tingkat pengetahuan, kecuali variabel aktivitas fisik. Hal ini berarti pengetahuan tentang gaya hidup sehat yang tinggi pada responden penelitian ini tidak sejalan dengan profil gaya hidup sehat yang baik, begitu pula sebaliknya. Gaya hidup yang sehat merupakan suatu tindakan yang menjadi kebiasaan sehari -hari. Menurut konsep cognitive behavioral, pengetahuan merupakan faktor intrapersonal yang penting. Akan tetapi, pengetahuan saja tidaklah cukup untuk memengaruhi tindakan seseorang. Terdapat faktor-faktor lain yang memberi pengaruh pada tindakan seseorang, misalnya faktor interpersonal dan faktor di tingkat komunitas. ${ }^{19}$ Hal ini menjelaskan temuan pada penelitian ini yaitu beberapa variabel gaya hidup sehat tidak mempunyai asosiasi dengan pengetahuan tentang gaya hidup sehat. Beberapa penelitian terdahulu juga menemukan hasil yang sama. ${ }^{20,21}$ Di lain pihak, beberapa penelitian mengemukakan hasil yang sebaliknya, yaitu terdapat asosiasi yang signifikan antara pengetahuan dengan praktik gaya hidup sehat. ${ }^{22,23}$ Asosiasi yang bermakna antara variabel aktivitas fisik dengan tingkat pengetahuan kemungkinan disebabkan pertanyaan tentang aktivitas fisik merujuk kepada "jalan kaki”, yaitu: "Apakah anda rutin melakukan olahraga atau aktivitas fisik ringan seperti berjalan kaki minimal 30 menit sehari". Pertanyaan ini sesuai dengan definisi aktivitas fisik dari WHO. ${ }^{14}$ Jawaban responden pada penelitian ini kemungkinan dikaitkan dengan pekerjaan dan kebiasaan mereka sehari-hari, baik laki-laki maupun 
perempuan, yang berjalan kaki ke ladang atau ke sawah.

Intervensi edukasi tentang gaya hidup sehat yang dilakukan pada penelitian ini mampu meningkatkan pengetahuan, dengan rata-rata skor semula 7,0 meningkat ke 8,0 setelah edukasi, dan ke 9,0 pada pengukuran satu bulan kemudian. Telah banyak penelitian yang membuktikan hal serupa bahwa edukasi tentang gaya hidup sehat dapat meningkatkan pengetahuan tentang gaya hidup sehat. ${ }^{23-25}$ Namun demikian, hasil dari penelitian ini menunjukkan bahwa tidak ada asosiasi yang bermakna antara profil gaya hidup sehat dan tingkat pengetahuan tentang gaya hidup sehat. Artinya, masyarakat pada populasi penelitian ini sudah menerapkan gaya hidup sehat dalam kehidupan mereka sehari-hari terlepas dari sebagian besar mereka mempunyai tingkat pengetahuan tentang gaya hidup sehat yang rendah atau tinggi, maupun sebagian besar mereka ternyata memiliki tingkat pendidikan terakhir yang rendah. Kebiasaan hidup sehat masyarakat pedesaan tampaknya berasal dari kearifan budaya lokal khas mayarakat pedesaan. Oleh karena itu, program promosi kesehatan di kalangan masyarakat pedesaan sebaiknya dapat mengakomodasi budaya dan kearifan lokal. ${ }^{26}$

Beberapa keterbatasan penelitian adalah sebagai berikut. Pertama, meskipun dalam penelitian ini diberikan intervensi kepada subjek penelitian, namun tidak ada kelompok kontrol. Kedua, tidak dikendalikan variabel pengacau yang mungkin ada, misalnya: faktor eksternal selama jeda intervensi yang mungkin dapat memengaruhi baseline. Sebagai contoh, pada saat jeda antara intervensi edukasi dan pengukuran pengetahuan setelah satu bulan berikutnya, responden mungkin menerima informasi tentang gaya hidup sehat sehingga dapat menambah pengetahuannya, namun hal ini tidak dikendalikan oleh tim peneliti. Ketiga, jumlah populasi terjangkau sebagai responden dalam penelitian ini mengacu pada jumlah populasi penelitian sebelumnya yang telah dilakukan pada populasi yang sama, yaitu 124 , namun yang bersedia berpartisipasi dalam penelitian ini hanya sebanyak 108 (response rate: $87 \%$ ). Di samping beberapa keterbatasan yang telah dikemukakan di atas, kelebihan penelitian ini adalah penelitian ini merupakan sebuah tindak lanjut dari temuan penelitian sebelumnya yang telah dilakukan pada populasi yang sama dengan penelitian ini, ${ }^{13}$ dengan demikian secara praktis penelitian intervensi ini merupakan hal yang nyata dan mendesak yang dibutuhkan oleh populasi sasaran.

\section{Simpulan}

Hasil penelitian ini membuktikan bahwa di kalangan masyarakat pedesaan di Desa Banjaroyo, Kalibawang, Kulon Progo, D.I. Yogyakarta, profil gaya hidup sehat dan tingkat pengetahuan tentang gaya hidup sehat pada sebagian masyarakatnya dikategorikan baik. Intervensi edukasi tentang gaya hidup sehat dapat meningkatkan pengetahuannya secara signifikan. Edukasi ini diperlukan dan sebaiknya diprogram oleh Dinas Kesehatan dengan target masyarakat pedesaan, untuk menjamin bahwa pengetahuan, kebiasaan, dan gaya hidup sehat yang telah dipraktikkan sehari-hari dapat selalu diperbaharui dan dilanjutkan ke generasi berikutnya.

\section{Ucapan Terima Kasih}

Tim peneliti mengucapkan terima kasih kepada Kepala Dusun Tanjung dan Dlingseng Desa Banjaroyo, Kecamatan Kalibawang, Kabupaten Kulonprogo, D.I. Yogyakarta yang telah mendukung proses pengambilan data, serta masyarakat setempat yang berkenan secara sukarela untuk berpartisipasi sebagai responden dalam penelitian ini. Tim peneliti juga mengucapkan terima kasih kepada para mahasiswa S1 Fakultas Farmasi Universitas 
Sanata Dharma yang telah terlibat dalam pengambilan data untuk penelitian ini.

\section{Pendanaan}

Penelitian ini diselenggarakan dengan dukungan dana Hibah Internal Lembaga Penelitian dan Pengabdian kepada Masyarakat Universitas Sanata Dharma tahun 2019.

\section{Konflik Kepentingan}

Seluruh penulis menyatakan tidak terdapat potensi konflik kepentingan dengan penelitian, kepenulisan (authorship), dan atau publikasi artikel ini.

\section{Daftar Pustaka}

1. Mottillo S, Filion KB, Genest J, Joseph L, Pilote L, Poirier P, et al. The metabolic syndrome and cardiovascular risk: A systematic review and meta-analysis. J Am Coll Cardiol 2010;56(14):1113-32. doi: 10.1016/j.jacc.2010.05.034

2. Grundy SM. Pre-diabetes, metabolic syndrome, and cardiovascular risk. J Am Coll Cardiol. 2012;59(7):635-43. doi: 10 .1016/j.jacc.2011.08.080

3. Soewondo P, Purnamasari D, Oemardi M, Waspadji S, Soegondo S. Prevalence of metabolic syndrome using NCEP/ATP III criteria in Jakarta, Indonesia. Acta Med Indones. 2010;42(4):199-203.

4. Jafar N. Sindroma metabolik dan epidemiologi. Media Gizi Masy Indones. 2012;1(2):71-8.

5. Oktavian A, Salim L, Krismawati H, Sandjaja B. Measurement of body mass index and metabolic syndrome among indigenous population in Jayapura City, Papua Province Indonesia. Obes Res Clin Pract. 2013;7(1):18. doi: 10.1016/j.orcp.2 013.08 .057

6. Suastika K, Dwipayana P, Saraswati
IMR, Gotera W, Gde Budhiarta AA, Dwi Sutanegara IN, et al. Prevalence of obesity, metabolic syndrome, impaired fasting glycemia, and diabetes in selected villages of Bali, Indonesia. J ASEAN Fed Endocr Soc. 2011;26(2):159-62. doi: 10. 15605/jafes.026.02.14

7. Sirait AM, Sulistiowati E. Sindrom metabolik pada orang dewasa di Kota Bogor, 2011-2012. Media Heal Res Dev. 2014;24(2):81-8.

8. Bantas K, Yosef HK, Moelyono B. Perbedaan gender pada kejadian sindrom metabolik pada penduduk perkotaan di Indonesia. J Kesehat Masy Nas. 2012; 7(5):219-26.

9. Fenty F, Widayati A, Virginia DM, Hendra P. Metabolic syndrome among Adults in Rural Area. Indones J Clin Pathol Med Lab. 2016;22(3):254-7. doi: 10.1016/j.pe p.2016.09.007

10. Kementerian Kesehatan Republik Indonesia. Hasil utama riskesdas 2018. Jakarta: Kementerian Kesehatan Republik Indonesia; 2018.

11. Eguchi E, So H, Honjo K, Tamakoshi A. Impact of healthy lifestyle behaviors and education level on cardiovascular mortality: The Japan collaborative cohort study. Circulation. 2016;133(1):P211.

12. National Cholesterol Education Program. ATP III guidelines at-a glance quick desk reference [Diunduh 3 Januari 2019]. Tersedia dari: https://www.nhlbi.nih.gov/ files/docs/guidelines/atglance.pdf

13. WidayatiA, Fenty F, Linawati Y. Hubungan antara pengetahuan, sikap, dan tindakan gaya hidup sehat dengan risiko penyakit kardiovaskular pada orang dewasa di pedesaan di Daerah Istimewa Yogyakarta. Indones J Clin Pharm. 2019;8(1):1-11. doi: 10.15416/ijcp.2019.8.1.1

14. World Health Organization. Global strategy on diet, physical activity and health. Geneva: World Health Organization. 
15. Taber KS. The use of cronbach's alpha when developing and reporting research instruments in science education. Res Sci Educ. 2018;48:1273-96. doi: 10.1007/ s1 1165-016-9602-2

16. Abdullahi A, Hassan A, Kadarman N, Saleh A, Baraya YS, Lua PL. Food safety knowledge, attitude, and practice toward compliance with abattoir laws among the abattoir workers in Malaysia. Int J Gen Med. 2016;9:79-87. doi: 10.2147/IJGM. S98436

17. Koo HC, Poh BK, Talib RA. Development, validity and reliability of a questionnaire on knowledge, attitude and practice (KAP) towards whole grain among primary school children in Kuala Lumpur, Malaysia. Int Food Res J. 2016; 23(2):797-805.

18. Kementerian Kesehatan Republik Indonesia. Riset kesehatan dasar 2013. Jakarta: Kementerian Kesehatan Republik Indonesia; 2013.

19. Conner M, Norman P. Health behaviour: Current issues and challenges. Psychol Heal [Diunduh 3 Januari 2019]. 2017;32 (8):895-906. doi: 10.1080/08870446.201 7.1336240

20. Sinaga SEN. Hubungan umur dan pengetahuan dengan gaya hidup sehat mahasiswa Akper Yatna Yuana Lebak. Mahakam Nurs J. 2018;2(3):114-9. doi: 10.35963/mnj.v2i3.109

21. Sajwani RA, Shoukat S, Raza R, Shiekh
MM, Rashid Q, Siddique MS, et al. Knowledge and practice of healthy lifestyle and dietary habits in medical and non-medical students of Karachi, Pakistan. J Pak Med Assoc. 2009;59(9): 650-5.

22. Askarian M, Dehghani Z, Danaei M, Vakili V. Knowledge and practice of medical students on healthy lifestyle: A cross-sectional study in Shiraz. J Heal Sci Surveill Syst. 2013;1(2):77-82.

23. Istiningtyas A. Hubungan antara pengetahuan dan sikap tentang gaya hidup sehat mahasiswa di PSIK UNDIP Semarang. J KesMaDaSKa. 2010;1(1):18 -25 .

24. Verma RK, Paraidathathu T, Taha NA, Chong WW. Perceptions of the Malaysian general public on community pharmacybased weight management services. J Pharm Policy Pract. 2018;11(1):17. doi: 10.1186/s40545-018-0146-x

25. Amarasekara P, de Silva A, Swarnamali H, Senarath U, Katulanda P. Knowledge, attitudes, and practices on lifestyle and cardiovascular risk factors among metabolic syndrome patients in an urban tertiary care institute in Sri Lanka. AsiaPacific J Public Heal. 2016;28(1):32S-40S. doi: 10.1177/1010539515612123

26. Demaio A. Local wisdom and health promotion: Barrier or catalyst? Asia Pac J Public Heal. 2011;23(2):127-32. doi: 10. $1177 / 1010539509339607$ 